\begin{tabular}{|c|c|c|c|c|c|}
\hline \multicolumn{6}{|c|}{ All-cause death } \\
\hline Male & Tertile of sCr & $<18.5$ & $18.5-24.9$ & 25.0-29.9 & $\geq 30.0$ \\
\hline \multirow{3}{*}{ Unadjusted } & Lowest & $5.85(5.37-6.36)^{\mathrm{a}}$ & $2.32(2.14-2.51)^{\mathrm{a}}$ & $1.20(0.98-1.46)$ & $1.24(0.76-2.00)$ \\
\hline & Middle & $1.56(1.37-1.78)^{\mathrm{a}}$ & Reference & $0.92(0.77-1.11)$ & $0.54(0.29-1.02)$ \\
\hline & Highest & $0.42(0.31-0.57)^{\mathrm{a}}$ & $0.38(0.34-0.43)^{\mathrm{a}}$ & $0.40(0.32-0.49)^{\mathrm{a}}$ & $0.48(0.31-0.75)^{b}$ \\
\hline \multirow{3}{*}{ Model 1} & Lowest & $4.68(4.30-5.10)^{\mathrm{a}}$ & $1.96(1.80-2.12)^{\mathrm{a}}$ & $1.22(1.00-1.48)$ & $1.74(1.07-2.84)^{\mathrm{c}}$ \\
\hline & Middle & $1.58(1.38-1.80)^{\mathrm{a}}$ & Reference & $1.03(0.86-1.24)$ & $0.88(0.46-1.66)$ \\
\hline & Highest & $0.64(0.47-0.86)^{b}$ & $0.52(0.46-0.59)^{\mathrm{a}}$ & $0.59(0.48-0.74)^{\mathrm{a}}$ & $1.00(0.63-1.57)$ \\
\hline \multirow{3}{*}{ Model 2} & Lowest & $4.74(4.35-5.17)^{\mathrm{a}}$ & $2.00(1.85-2.17)^{\mathrm{a}}$ & $1.27(1.04-1.54)^{\mathrm{c}}$ & $1.82(1.12-2.97)^{\mathrm{c}}$ \\
\hline & Middle & $1.56(1.37-1.79)^{\mathrm{a}}$ & Reference & $1.05(0.87-1.27)$ & $0.91(0.48-1.73)$ \\
\hline & Highest & $0.66(0.49-0.89)^{\mathrm{b}}$ & $0.54(0.48-0.61)^{\mathrm{a}}$ & $0.63(0.50-0.78)^{\mathrm{a}}$ & $1.09(0.69-1.72)$ \\
\hline \multirow{3}{*}{ Model 3} & Lowest & $3.57(3.26-3.92)^{\mathrm{a}}$ & $1.63(1.49-1.77)^{\mathrm{a}}$ & $1.04(0.85-1.28)$ & $1.38(0.83-2.28)$ \\
\hline & Middle & $1.58(1.38-1.81)^{\mathrm{a}}$ & Reference & $0.99(0.82-1.20)$ & $0.78(0.41-1.47)$ \\
\hline & Highest & $0.73(0.54-0.99)^{\mathrm{c}}$ & $0.57(0.51-0.65)^{\mathrm{a}}$ & $0.63(0.50-0.79)^{\mathrm{a}}$ & $0.96(0.61-1.52)$ \\
\hline
\end{tabular}

\title{
All-cause death
}

Female

Categories of BMI $\left(\mathrm{kg} / \mathrm{m}^{2}\right)$

\begin{tabular}{|c|c|c|c|c|c|}
\hline & \multirow[b]{2}{*}{ Tertile of $\mathbf{s C r}$} & \\
\hline & & $<18.5$ & $18.5-24.9$ & 25.0-29.9 & $\geq \mathbf{3 0 . 0}$ \\
\hline \multirow{3}{*}{ Unadjusted } & Lowest & $5.55(4.93-6.24)^{\mathrm{a}}$ & $2.72(2.41-3.07)^{\mathrm{a}}$ & $1.56(1.22-2.00)^{\mathrm{a}}$ & $1.86(1.15-3.01)^{\mathrm{c}}$ \\
\hline & Middle & $1.11(0.94-1.32)$ & Reference & $0.84(0.64-1.12)$ & $1.42(0.87-2.32)$ \\
\hline & Highest & $0.26(0.18-0.35)^{\mathrm{a}}$ & $0.35(0.29-0.42)^{\mathrm{a}}$ & $0.39(0.27-0.55)^{\mathrm{a}}$ & $0.47(0.24-0.91)^{\mathrm{c}}$ \\
\hline \multirow{3}{*}{ Model 1} & Lowest & $4.47(3.97-5.04)^{\mathrm{a}}$ & $2.28(2.02-2.58)^{\mathrm{a}}$ & $1.51(1.17-1.93)^{b}$ & $2.17(1.34-3.52)^{b}$ \\
\hline & Middle & $1.17(0.98-1.39)$ & Reference & $0.90(0.68-1.19)$ & $1.82(1.12-2.98)^{\mathrm{c}}$ \\
\hline & Highest & $0.39(0.28-0.54)^{\mathrm{a}}$ & $0.50(0.42-0.60)^{\mathrm{a}}$ & $0.55(0.38-0.79)^{b}$ & $0.80(0.41-1.57)$ \\
\hline \multirow{3}{*}{ Model 2} & Lowest & $4.48(3.97-5.05)^{\mathrm{a}}$ & $2.32(2.05-2.63)^{\mathrm{a}}$ & $1.54(1.20-1.98)^{b}$ & $2.23(1.37-3.63)^{b}$ \\
\hline & Middle & $1.16(0.98-1.38)$ & Reference & $0.90(0.68-1.20)$ & $1.87(1.14-3.07)^{\mathrm{c}}$ \\
\hline & Highest & $0.40(0.29-0.55)^{\mathrm{a}}$ & $0.52(0.43-0.63)^{\mathrm{a}}$ & $0.58(0.40-0.83)^{\mathrm{b}}$ & $0.86(0.44-1.68)$ \\
\hline \multirow{3}{*}{ Model 3} & Lowest & $3.48(3.07-3.94)^{\mathrm{a}}$ & $1.78(1.57-2.03)^{\mathrm{a}}$ & $1.15(0.89-1.49)$ & $1.53(0.93-2.53)$ \\
\hline & Middle & $1.26(1.06-1.50)^{\mathrm{c}}$ & Reference & $0.77(0.58-1.03)$ & $1.48(0.90-2.43)$ \\
\hline & Highest & $0.46(0.33-0.64)^{\mathrm{a}}$ & $0.53(0.44-0.64)^{\mathrm{a}}$ & $0.50(0.35-0.72)^{\mathrm{a}}$ & $0.65(0.33-1.28)$ \\
\hline
\end{tabular}

Data are expressed as odds ratio (95\% confidence interval) compared to the reference group of BMI 18.5-24.9 with middle tertile of sCr. Model 1: adjusted for age

Model 2: adjusted for age, dialysis vintage, diabetes mellitus

Model 3: adjusted for age, dialysis vintage, diabetes mellitus, serum albumin, phosphorus, C-reactive protein , Kt/V ${ }^{\mathrm{a}} \mathrm{p}<0.001,{ }^{\mathrm{b}} \mathrm{p}<0.01,{ }^{\mathrm{c}} \mathrm{p}<0.05 \quad$ Abbreviation: BMI, body mass index; $\mathrm{sCr}$, serum creatinine 